\title{
Predicting growth and development of pigeonpea: leaf area development
}

\author{
R. Ranganathan ${ }^{\mathrm{a}, 1}$, Y.S. Chauhan ${ }^{\mathrm{a}}$, D.J. Flower ${ }^{\mathrm{a}}$, \\ M.J. Robertson ${ }^{\text {b,* }}$, C. Sanetra ${ }^{a}$, S.N. Silim ${ }^{\mathrm{a}}$ \\ ${ }^{a}$ International Crops Research Institute for the Semi-Arid Tropics, Patancheru, PO 502 324, AP, India \\ ${ }^{\mathrm{b}}$ CSIRO Sustainable Ecosystems, Agricultural Production Systems Research Unit, 120 Meiers Rd, Indooroopilly, Qld 4067, Australia
}

Received 19 June 1998; received in revised form 5 January 2000; accepted 11 October 2000

\begin{abstract}
Relationships are developed that describe the processes of node production, leaf appearance and senescence, and leaf size in pigeonpea in relation to temperature, plant density and maturity type. The rate of node production until flowering in relation to thermal time was found to be unaffected by season and plant density in the range of 4-33 plants $\mathrm{m}^{-2}$. Maturity type did not affect the rate of node production on the main stem or the rate of appearance of leaves on the plant. The rate of senescence of main-stem nodes in relation to thermal time was unaffected by plant density and growth duration. The functions developed in this paper can be used to predict the temporal changes in leaf area development in crop growth models. (C) 2001 Elsevier Science B.V. All rights reserved.
\end{abstract}

Keywords: Cajanus cajan; Leaf area development; Model; Pigeonpea

\section{Introduction}

Leaf area development involves the production of new leaves, increase in the size of existing leaves and the senescence of old leaves. It is a fundamental process of crop production as leaves intercept solar radiation and produce carbohydrates through photosynthesis. The production, expansion and survival of green leaf area are important determinants of crop productivity, as are the relative durations of the vegetative and reproductive phases. There is a wide diversity in time to flowering and maturity of pigeonpea

\footnotetext{
* Corresponding author.

E-mail address: michael.robertson@tag.csiro.au (M.J. Robertson).

${ }^{1}$ Present address: KWS Saat AG, PO Box 1463, D 37555 Einbeck, Germany.
}

(Cajanus cajan (L.) Millspaugh) and cultivars differ in growth habit and plant canopy characteristics. Growth habit mainly depends on the number of primary and secondary branches and the angle of branches on the stem on which they are borne resulting in a continuous variety of forms from upright to spreading (Remanandan, 1990). Genotypic differences have been reported for leaf size which are in turn influenced by the growing environment (ICRISAT, 1975, 1976). Pigeonpea is sown at a wide range of plant densities depending on the growth duration of the cultivar, the cropping season and system. The classification of maturity duration used here is based on time to flower when the crop is sown soon after the summer solstice at ICRISAT $\left(17^{\circ} 48^{\prime} \mathrm{N}\right)$. Photoperiod-sensitive mediumduration cultivars (160-190 days maturity) cropped in June/July, soon after the summer solstice, are sown at 
plant densities of 6-8 plants $\mathrm{m}^{-2}$. These same cultivars are grown at 33 plants $\mathrm{m}^{-2}$ in sowings approaching the winter solstice. Shorter-duration cultivars are cropped at 33 plants $\mathrm{m}^{-2}$ in all seasons (Chauhan, 1990).

Currently most of the world's pigeonpea cultivation is in the tropics where it is sown at the commencement of the rainy season, but interest in pigeonpea is expanding into new cropping environments and systems (Singh et al., 1990, 1996). Models that simulate the growth and development of a crop are a useful tool to examine environmental constraints to production. The ability to predict leaf area development is central to the objective of simulating the growth and development of pigeonpea. There are no reports in the literature of attempts to analyse canopy development in pigeonpea for the purpose of modelling. This paper examines the physiology of leaf area development in pigeonpea with a view to develop relationships that predict green leaf area. To this end the paper reanalyses published data and reports new experimental data collected at the International Crops Research Institute for the Semi-Arid Tropics (ICRISAT), India $\left(17^{\circ} 48^{\prime} \mathrm{N}\right)$. Although genotypic differences have been reported for growth habit and leaf size, the parameters that describe leaf area dynamics here are based on physiological processes that are expected to apply over a wide range of cultivars. Few studies on pigeonpea have compared leaf area development across seasons, maturity groups and plant densities. The modification of leaf area by these factors is examined here. Water limitations and nutrition, which also affect leaf area dynamics, are not considered in this study.

\section{Materials and methods}

\subsection{Data}

Functions describing rates of node and leaf production, and senescence were developed by re-analysing data collected in experiments described in detail in Narayanan et al. (1981), Sheldrake and Narayanan (1979), ICRISAT (1980) and Sanetra (1996) (Table 1). In addition, three trials were conducted in the rainy seasons of 1990-1991 and 1994-1995 to develop and test the required functions (Table 1). Relevant experimental details of these studies are given below.

In study 1, node appearance of three pigeonpea cultivars was recorded during the rainy season of 1990, in monthly sowings from June to December

Table 1

Summary of data sets used for establishing relationships for leaf area development. All studies were conducted under irrigated conditions in the field at ICRISAT Centre, Patancheru, India $\left(17^{\circ} 48^{\prime} \mathrm{N}\right)$, with the exception of Turnbull (1986) which was conducted in a controlled environment

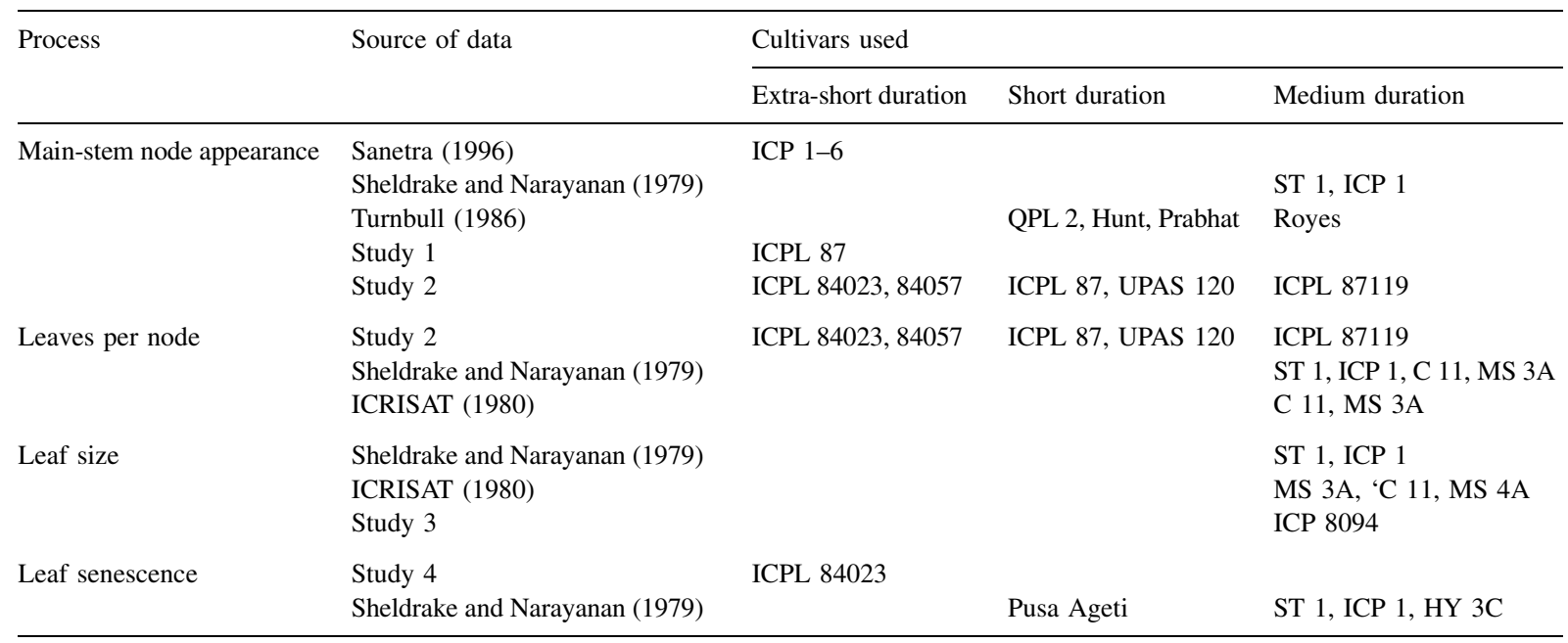


at ICRISAT, Patancheru, India. Pots of $30 \mathrm{~cm}$ diameter were laid out in a three-replicate split-plot design with sowing dates as main plots. Cultivars were assigned to sub-plots. Only data for the short-duration cultivar ICPL 87 are presented here. The pots were placed in the open and irrigated to field capacity at regular intervals. Appearance of nodes on the main stem were measured at regular intervals for all sowings.

In study 2, data on leaf area development of diverse cultivars was measured at ICRISAT, Patancheru, India. In the rainy season of 1990 on 3 July, nine pigeonpea cultivars from three maturity groups were sown in a split-plot experiment with three replicates. Extra-short (100-110 days to maturity) and shortduration (120-140 days) cultivars were sown at a density of 33 plants $\mathrm{m}^{-2}$ while medium-duration cultivars were sown at 6.7 plants $\mathrm{m}^{-2}$. Main plots were water supply regimes by irrigation or rainfall. Irrigated plots were watered at regular intervals to prevent water stress. Only irrigated data are used here. Cultivars with similar growth duration formed sub-plots and measured $9 \mathrm{~m} \times 6 \mathrm{~m}$. As part of the growth analysis, nodes on the main stem were counted at 7-10 day intervals in the early and post-flowering growth stages, and at 14day intervals in the vegetative stage.

In study 3, conducted in the rainy season of 1994, growth by an extra-short, short- and medium-duration pigeonpea was measured under irrigated and rainfed conditions. The experiment was laid out as a split-plot with four replications. Data on the rate of leaf senescence for the extra-short, short- and medium-duration cultivars was used to develop the relationships between thermal time and rate of leaf senescence after flowering.

In all three studies a basal application of di-ammonium phosphate at the recommended rate of $100 \mathrm{~kg} \mathrm{ha}^{-1}$ was applied. Plots were weeded manually at regular intervals in the early growth stages until canopy closure. Insecticides were used at frequent intervals, starting from the time of flowering, to control insect pest damage, especially that caused by Helicoverpa armigera. In all data sets listed in Table 1 a node was defined at that which subtended a fully expanded leaf. Once senescence of leaves began, the total number of nodes on the main stem of the plant was counted by adding the number of visible leaf scars to the number of fully expanded green leaves still attached to the main stem.

\subsection{Data analysis}

Plant leaf area was analysed in terms of the functional relationships between thermal time and mainstem node appearance, between main-stem nodes and leaves per plant, the distribution of individual leaf area by node, and between leaf senescence and thermal time. Daily thermal time (TT) was calculated using the formulae

$\mathrm{TT}= \begin{cases}T_{\text {average }}-T_{\mathrm{b}} & \text { for } T_{\text {average }} \leq T_{\mathrm{o}} \\ \frac{T_{\mathrm{c}}-T_{\text {average }}}{T_{\mathrm{c}}-T_{\mathrm{o}}}\left(T_{\mathrm{o}}-T_{\mathrm{b}}\right) & \text { for } T_{\mathrm{o}}<T_{\text {average }}<T_{\mathrm{c}}\end{cases}$

where $T_{\mathrm{b}}, T_{\mathrm{o}}$ and $T_{\mathrm{c}}$ are base, optimum and ceiling temperatures for leaf growth and $T_{\text {average }}$ is the mean daily temperature.

\section{Results and discussion}

\subsection{Leaf appearance}

\subsubsection{Main-stem nodes}

No published data are available on the cardinal temperatures for leaf production in pigeonpea. Turnbull (1986) grew pigeonpea in temperature-controlled glasshouses at 12- and 16-h photoperiods and recorded the appearance of main-stem nodes until floral initiation. The data from this experiment were re-analysed to determine the cardinal temperatures and phyllochron for node appearance. The experiment was conducted using a combination of day and night temperatures ranging from 16 to $32^{\circ} \mathrm{C}$ as treatments. There was a constant rate of appearance of main-stem nodes in all temperature treatments (data for $16 \mathrm{~h}$ daylength presented in Fig. 1). The rate of appearance of main-stem nodes is a linear function of the daily mean temperature in the range from 20 to $32^{\circ} \mathrm{C}$. McPherson et al. (1985) also found that the rate of node appearance increased in the range of $16-32^{\circ} \mathrm{C}$, suggesting that the optimum temperature is close to $32^{\circ} \mathrm{C}$. A base temperature of $11.9^{\circ} \mathrm{C}$ and phyllochron of $20^{\circ} \mathrm{Cd}$ was estimated from the linear regression of Turnbull's data, with $R^{2}=0.89$. The slopes of responses for plants exposed to 12 and $16 \mathrm{~h}$ photoperiods were not significantly $(P<0.05)$ different. A fitted base temperature of $11.9^{\circ} \mathrm{C}$ is higher than a modal value derived from numerous germination 


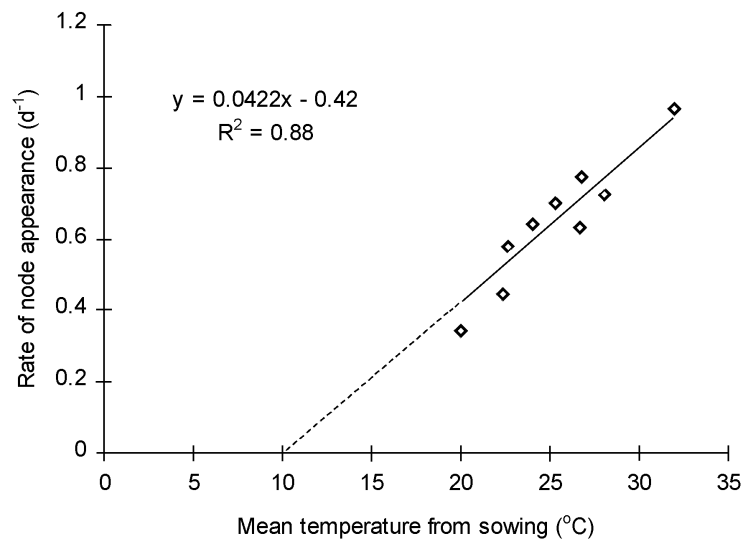

Fig. 1. Rate of node appearance on the main stem (measured in a 16-h day) as a function of mean temperature. Data from Turnbull (1986).

and emergence studies, which suggest a value for the base temperature closer to $10^{\circ} \mathrm{C}$ (Carberry et al., 2001). When the regression is fitted with the base temperature set to $10^{\circ} \mathrm{C}$ the $R^{2}$ value decreased slightly to 0.88 and the phyllochron increased to $24^{\circ} \mathrm{Cd}$ per node.

The consistency of these derived parameters across seasons, soil types and plant densities (4 and 33 plants $\mathrm{m}^{-2}$ ) was verified by re-analysing data from experiments of Sheldrake and Narayanan (1979), Sanetra (1996) and study 1. The number of nodes on the main stem was plotted against accumulated thermal time, calculated with a base temperature of $10^{\circ} \mathrm{C}$ and optimum of $32^{\circ} \mathrm{C}$. There was strong linear relationship between the observed number of nodes on the main stem measured until flowering and the accumulated thermal time, the $R^{2}$ exceeded 0.89 (Fig. 2a and $b$ ). The fitted phyllochron for main-stem nodes, calculated as the inverse of the fitted regression slope, varied between 32 and $45^{\circ} \mathrm{Cd}^{-1}$. While these values are greater than those of Turnbull (1986) there was no significant $(P<0.05)$ difference between the three studies. These values derived for pigeonpea are similar to those for other warm-season legumes. For example, Craufurd et al. (1997) quote a mean value for cowpea of $42^{\circ} \mathrm{Cd}$ per leaf above a base temperature that varied from 7 to $12^{\circ} \mathrm{C}$, derived from numerous field sowings. Leong and Ong (1983) derived a phyllochron of $56^{\circ} \mathrm{Cd}$ for peanut in controlled environment studies.

No published data or information are available on the effect of crop duration on the rate of node appear- (a)

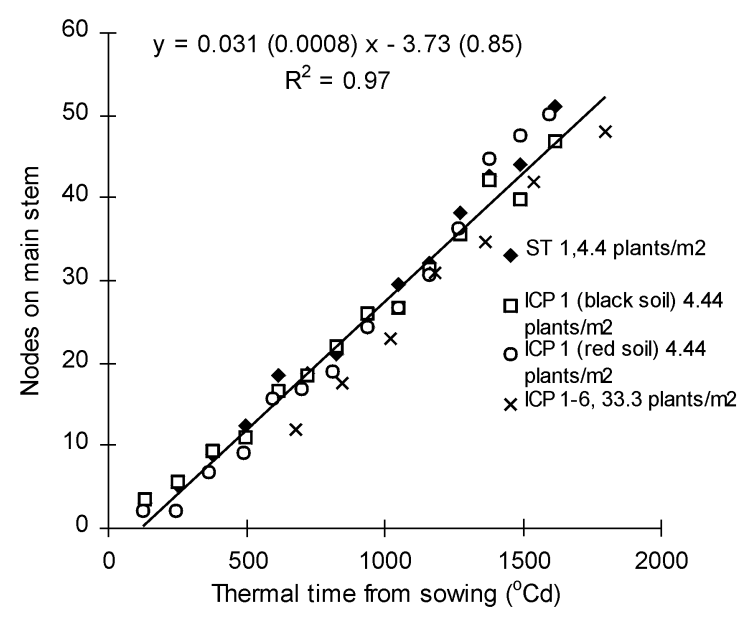

(b)

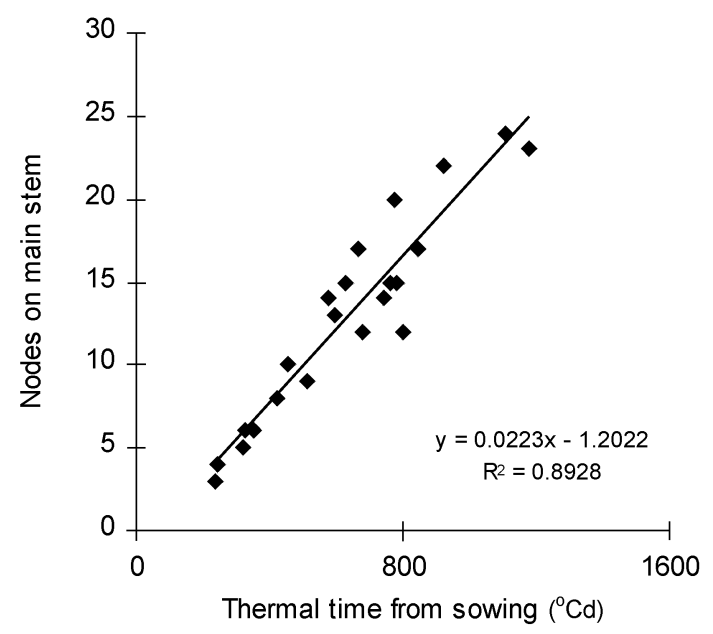

Fig. 2. Appearance of nodes as a function of thermal time. Original data of (a) Sheldrake and Narayanan (1979) and Sanetra (1996); (b) study 1 (see Table 1).

ance. Fig. 3 presents node appearance as a function of accumulated thermal time from sowing for indeterminate medium-duration, determinate and indeterminate short-duration, and determinate and indeterminate extra-short duration pigeonpea (Sheldrake and Narayanan, 1979; Sanetra, 1996, study 2 data). Indeterminate cultivars are defined for the purposes of this paper as being those that have the capacity to continue 


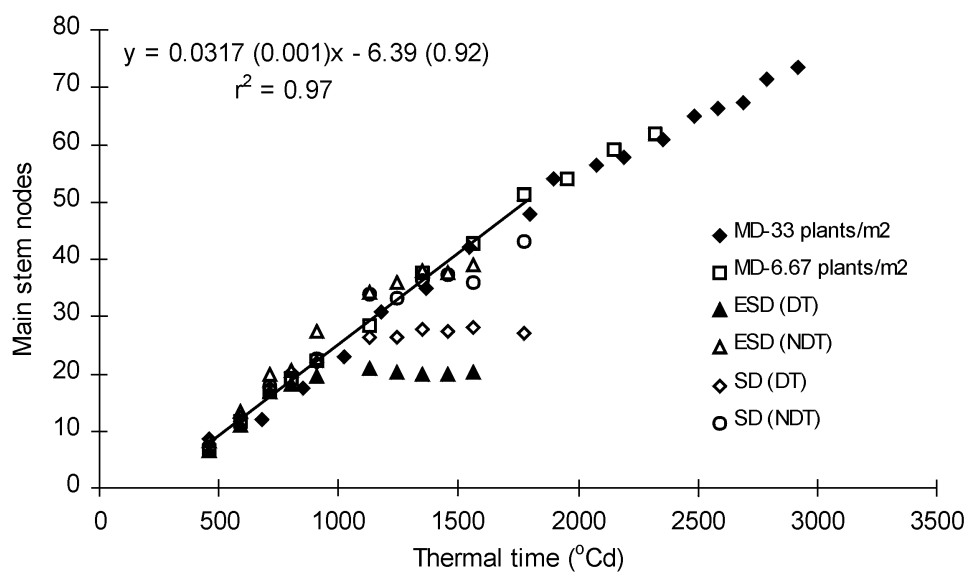

Fig. 3. Main-stem node appearance as a function of thermal time for indeterminate (NDT) and determinate (DT), short-duration (SD) and extra-short duration (ESD) cultivars, and a medium-duration (MD) cultivar at a low and high plant population density (data from Sanetra, 1996 and study 2). A linear regression is fitted to the initial portion of the plot where main-stem nodes is a linear function of accumulated thermal time.

to produce leaves until maturity. A linear relationship is a good approximation of the rate at which nodes appear on the main stem until flowering. The slope of the linear function in Fig. 3 establishes a phyllochron of $31.5^{\circ} \mathrm{Cd}$ for all cultivars, irrespective of growth duration and level of determinacy. After flowering, the rate at which nodes are produced tends to slow for indeterminate cultivars, whereas nodes do not develop on the main stem of determinate types after flowering. Also shown in Fig. 3 is node appearance for two contrasting plant population densities (4 and 33 plants $\mathrm{m}^{-2}$ ) for a single medium-duration cultivar. Node appearance rates are similar for the two densities, suggesting that in this range, plant density does not affect rate of node appearance on the main stem.

\subsubsection{Leaves}

In pigeonpea, more than one leaf can be associated with each main-stem node, i.e. branching can occur. Primary branches begin to appear progressively at the basal main-stem nodes after the appearance of 8-10 leaves on the main stem (Sheldrake and Narayanan, 1979). Nodes develop on primary branches and subsequently, secondary and tertiary branches, resulting in leaf number increasing exponentially. The appearance of branches has been successfully analysed in terms of thermal time, suggesting that there may be some conservative relationships between the number of main-stem nodes and total number of leaves on a plant. For example, Leong and Ong (1983) showed for peanut that branches appeared every $100^{\circ} \mathrm{Cd}$. It is important when attempting to characterise the potential rate of leaf appearance to consider only low plant densities where inter-plant competition is minimal and hence branching potential can be expressed to its maximum. In Fig. 4, leaf appearance on the plant is plotted as a function of the number of main-stem nodes for a number of medium-duration cultivars all sown at a plant population density of 4 plants $\mathrm{m}^{-2}$. Leaves on primary branches appear only after the development of 17-20 nodes on the main stem (Sheldrake and Narayanan, 1979; study 4). Thereafter, the number of leaves per plant appear at a rate faster than the number of main-stem nodes, as indicated by the fitted slope of 10.2 leaves per node for the second phase of the relationship.

The data in Fig. 4 suggest that there is little difference among a number of medium-duration cultivars for leaf number production. Data in Fig. 5 show leaf appearance plotted versus thermal time for a range of maturity types at contrasting densities. At the low density of 4.4 plants $\mathrm{m}^{-2}$, leaves appear at 0.4 leaves ${ }^{\circ} \mathrm{Cd}^{-1}$, while at high density, where inter-plant competition for assimilates for leaf growth is greater, the rate is 0.07 leaves per ${ }^{\circ} \mathrm{Cd}$. Significantly, at both densities there is no consistent effect of cultivar maturity on leaf production. For example, cultivars T 21 and Pusa Ageti mature in 140 and 168 days, 


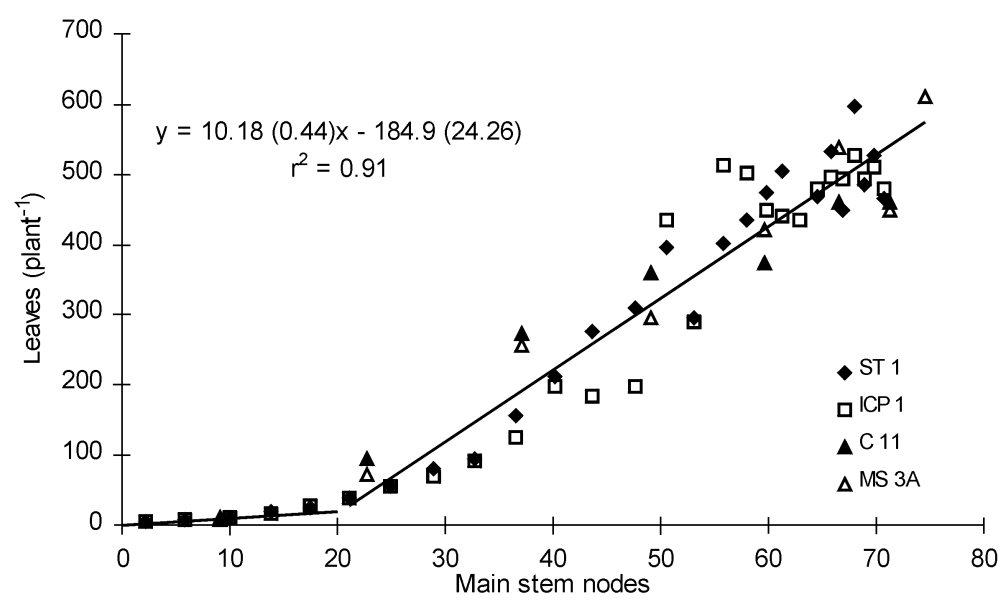

Fig. 4. Leaf appearance as a function of main-stem nodes for medium-duration pigeonpea (Sheldrake and Narayanan, 1979; ICRISAT, 1980).

respectively, while ST 1 and ICP 1 reach physiological maturity in 182 days (Fig. 5a). In Fig. 5b crops were sown at 33 plants $\mathrm{m}^{-2}$ but in different seasons. ICPL 84023 (104 days) and ICPL 87 (125 days) were grown in June at the start of the rainy season (study 4), and C 11 and ICP 7065 were sown in October in the postrainy season and matured in 110 days (ICRISAT, 1980). In summary, the data examined suggest that the rate of appearance of leaves on a plant, measured until flowering, is a function of plant density and is not dependent on cultivar or maturity type. Closely spaced plants have fewer leaves because primary branches do not attain their full size. Fewer secondary and tertiary branches are produced per plant when a crop is grown at high plant densities (Chauhan, unpublished data).

\subsection{Leaf expansion}

A number of authors has shown that the size of newly fully expanded leaves varies in a predictable manner with nodal position. The maximum size of newly expanded leaves increases with ontogenetic position for several weeks following emergence, thereafter the size of new leaves either changes little

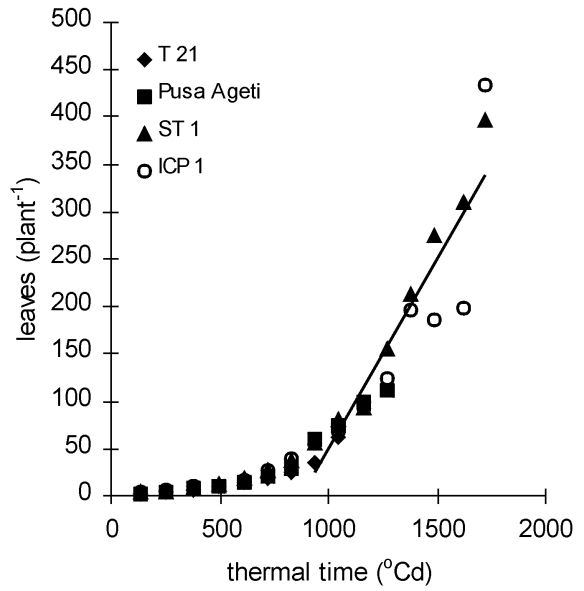

b.

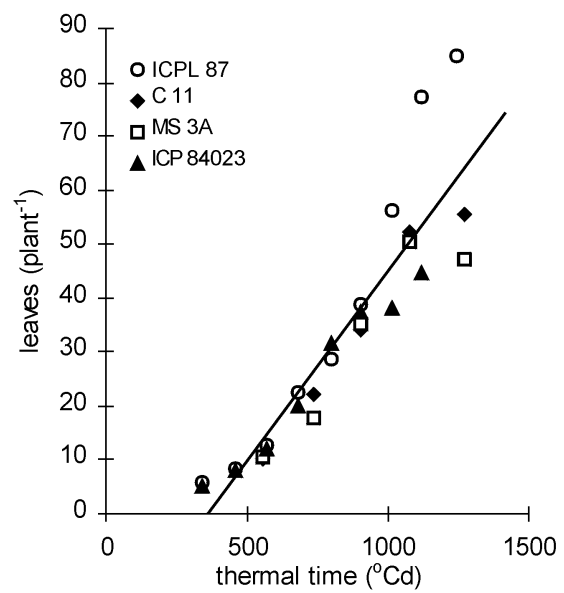

Fig. 5. Leaf appearance as a function of thermal time for crops sown at plant densities: (a) 4.4 plants $\mathrm{m}^{-2}, y=0.40(0.03) x-353.86(43.81)$, $R^{2}=0.87$ (Sheldrake and Narayanan, 1979); (b) 33 plants $\mathrm{m}^{-2}, y=0.071(0.006) x-25.57(5.39), R^{2}=0.84$ (ICRISAT, 1980). 
or more commonly decreases (see Littleton et al., 1979 for cowpea; Cao et al., 1988 for soybean). Littleton et al. showed that the ontogenetic change in leaf size was caused by corresponding changes in the thermal rate of leaf expansion $\left(\mathrm{cm}^{2}{ }^{\circ} \mathrm{Cd}^{-1}\right)$.

In a controlled environment study Flower (1986) demonstrated that pigeonpea leaves attain a size in relation to their position on the main-stem. Leaf size in pigeonpea increases exponentially from the size of the first trifoliate leaf with increase in main-stem node number until a maximum leaf size is reached after which leaf area declines. Leaf size increases in a similar fashion on secondary and tertiary branches. Rawson and Constable (1981) observed that pigeonpea leaves grew from 5 to $95 \%$ of their final leaf area in 18-22 days and that average rates of expansion were from 4 to $6 \mathrm{~cm}^{2}$ per day.

Data sets containing measurements of the size of individual leaves on a pigeonpea plant are rare. However, the effect of changes in leaf size with ontogeny needs to be accounted for and a relationship between leaf size and main-stem node number has been estimated by an alternative approach. An average leaf size has been calculated by dividing green leaf area of the plant by the number of leaves present. In Fig. 6, from the original data of Sheldrake and Narayanan (1979) and ICRISAT (1980) average leaf size is plotted against main-stem nodes for five medium-duration and one perennial pigeonpea cultivars (Ranganthan, unpublished data). The scatter suggests that there is little genotypic difference for leaf size in mediumduration cultivars. ICP 8094 was initially sown at 12 plants $\mathrm{m}^{-2}$ and thinned at regular intervals to 1.5 plants $\mathrm{m}^{-2}$ to simulate a crop grown with no inter-plant competition, in an attempt to maximise individual leaf size. Average leaf size in this crop was slightly greater than that of the others and forms an outer envelope to the average leaf size of the other cultivars. In agreement with Flower (1986), average leaf size increases to a maximum and declines rapidly after flowering. The decline in average leaf size is explained by the abscission of older leaves that have reached their maximum size. Since few leaves (relative to the number at flowering) are produced after flowering, leaves that remain on the plant (and whose leaf area is measured) are small and never achieve their potential size because carbon is partitioned to grain at that time.

\subsection{Leaf senescence}

Leaf senescence is an integral aspect of plant development. Prior to flowering, leaf senescence in irrigated crops is associated with the death of old leaves at the base of the canopy due to age and shading. Sanetra et al. (1998) divided the main stem

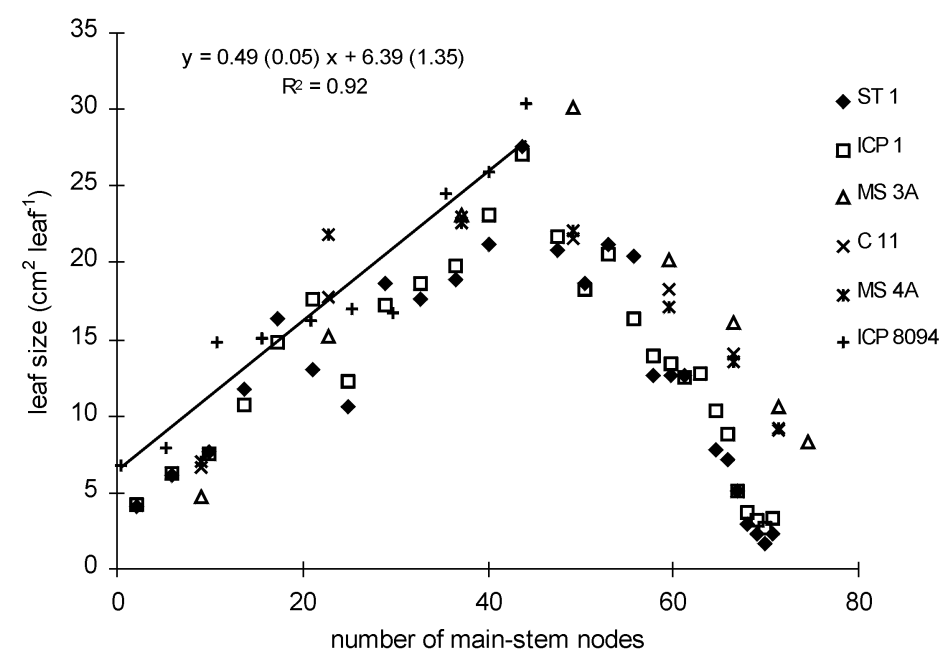

Fig. 6. Change in mean leaf size with number of main-stem nodes in medium-duration and perennial pigeonpea (data from Sheldrake and Narayanan, 1979; ICRISAT, 1980, study 3). The line is fitted by eye to data for IC 8094 and represents a crop grown with no inter-plant competition (see text for details). 
of plants into four fractions and measured the percentage of attached leaflets days after full expansion of the youngest leaf in each fraction. Leaflet abscission was most rapid in the bottom layer and about 45 days after full expansion, the percentage of attached leaflets dropped to less than 5\%. In contrast, close to $40 \%$ leaflets remained attached in the next layer. At flowering less than $10 \%$ of all leaflets in the bottom layer were still attached. The low photosynthetic rate does not provide the energy costs associated with maintenance respiration. Leaves that were 30-50 days old had rapidly declining rates of photosynthesis but not of transpiration (Rawson and Constable, 1981). After flowering, leaf senescence is associated with the translocation of nitrogen from the leaves to the grain (Sinclair and de Wit, 1975; Sanetra et al., 1998). In all data sets examined, LAI reached a maximum soon after flowering and decreased sharply thereafter. Even in indeterminate cultivars the same pattern was observed as loss in leaves due to senescence overtakes gain.

An attempt was made to relate the rate of leaf area senescence after flowering to thermal time. While the systematic effects of temperature on senescence are still uncertain, generally, leaves remain greener at lower temperature, and sometimes the period of "greeness" can be related to a developmental duration (e.g. Littleton et al., 1979 for cowpea).
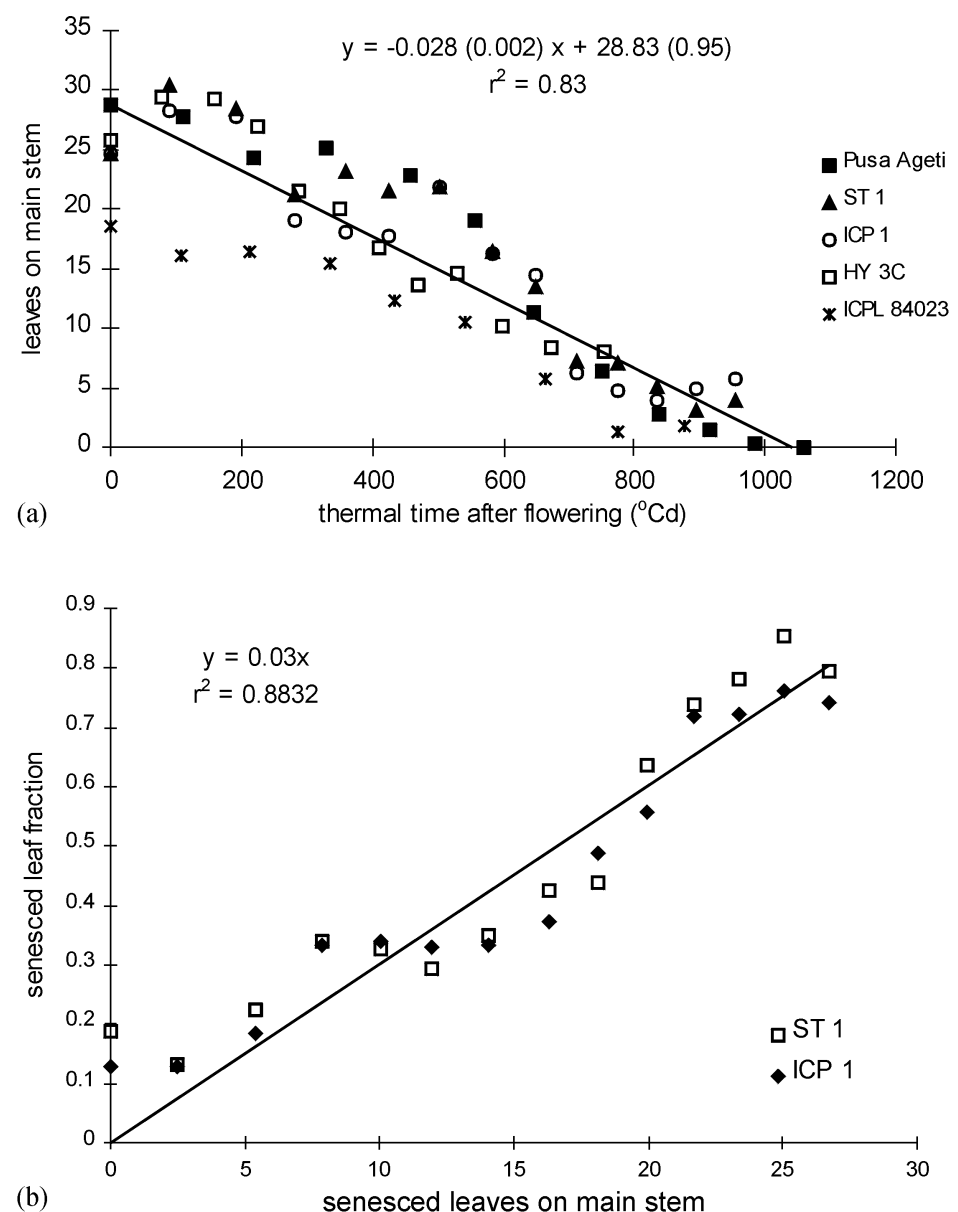

Fig. 7. (a) Number of nodes on the main stem bearing green leaves plotted as a function of cumulative thermal time since flowering. Data from Sheldrake and Narayanan (1979) and study 2. (b) Change in the senesced leaf fraction (senesced leaves per plant as a fraction of total leaves per plant) with number of nodes on the main stem bearing senesced leaves on the main stem. Data of Sheldrake and Narayanan (1979). 
The number of main-stem nodes bearing green leaves decreased in a linear fashion with thermal time elapsed since flowering (Fig. 7a) (Sheldrake and Narayanan, 1979; study 4). The constant rate of main-stem leaf senescence was similar for pigeonpea of different duration groups (ICPL 84023, extra short; Pusa Ageti, short; ST 1, ICP 1 and HY 3C, medium) and when grown at densities ranging from 4 to 33 plants $^{-2}$ (Pusa Ageti, ST 1, ICP 1 and HY 3C, 4.44 plants $\mathrm{m}^{-2}$; ICPL 84023, 33 plants $\mathrm{m}^{-2}$ ). After flowering, a thermal time of $35.7^{\circ} \mathrm{Cd}$ was required for each main-stem leaf to senesce. As each main-stem node senesces, 0.03 of the total number of leaves on the plant also senescence (Fig. 7b).

\section{Conclusions}

The functions described above form the basis of a model of potential canopy leaf area expansion and senescence, incorporating effects of temperature and cultivar maturity. Node appearance until flowering can be predicted from thermal time, with the degree of node appearance after flowering being a function of the degree of determinacy and carbon availability for leaf growth. The potential rate of leaf production per node is similar for a wide range of cultivar maturities and cultivars within each maturity class. Density has a significant effect on leaf appearance per main-stem node, presumably mediated through inter-plant competition for assimilate for leaf growth. Models of canopy expansion dealing should be able to accommodate such competition effects at high densities. A comparison of canopy development in different duration groups shows that rates of node production, leaf production and senescence are similar for cultivars across duration groups, and flowering is the key developmental event that moderates these rates. The group of functional relationships presented here can, with biomass accumulation and partitioning in pigeonpea, form the basis for a simulation model.

\section{Acknowledgements}

The authors would like to acknowledge the help provided by Anil Kumar, Gayatri Devi, J. Dimes, G.J. O’Leary, R.C. Nageswara Rao, R. Vanderlip and P.S.
Carberry for their assistance and comments. The staff of the Agronomy Division played a vital role in finding original records of data collected at ICRISAT as early as 1974. This research was supported by funding from the Australian Centre for International Agricultural Research.

\section{References}

Cao, J., Hesketh, J.D., Zur, B., Reid, J.F., 1988. Leaf area development in maize and soybean plants. Biotronics 17, 9-15.

Carberry, P.S., Ranganathan, R., Reddy, L.J., Chauhan, Y.S., Robertson, M.J., 2001. Predicting growth and development of pigeonpea: flowering response to photoperiod. Field Crops Res. 69, 151-162.

Chauhan, Y.S., 1990. Optimum agronomic management. In: Nene, Y.L., Hall, S.D., Sheila, V.K. (Eds.), The Pigeonpea. CAB International, Wallingford, Oxon., UK, pp. 257-278.

Craufurd, P.Q., Subedi, M., Summerfield, R.J., 1997. Leaf appearance in cowpea: effects of temperature and photoperiod. Crop Sci. 37, 167-171.

Flower, D.J., 1986. The role of osmotic adjustments in the water stressed leaves of pigeonpea (Cajanus cajan (L.) Millsp.). Ph.D. Thesis. University of Queensland, Brisbane, Qld, Australia.

ICRISAT, 1975. Pulse Physiology Progress Report 1974-75. Part I: Pigeonpea Physiology. Legumes Program, ICRISAT, Patancheru, AP, India (limited distribution).

ICRISAT, 1976. Pulse Physiology Progress Report 1975-76. Part I: Pigeonpea Physiology. Legumes Program, ICRISAT, Patancheru, AP, India (limited distribution).

ICRISAT 1980. Pulse Physiology Progress Report 1979-80. Part I: Pigeonpea Physiology. Legumes Program, ICRISAT, Patancheru, AP, India (limited distribution).

Leong, S.K., Ong, C.K., 1983. The influence of temperature and soil water deficit on the development and morphology of groundnut (Arachis hypogaea L.). J. Exp. Bot. 34, 1551-1561.

Littleton, E.J., Dennett, M.D., Elston, J., Monteith, J.L., 1979. The growth and development of cowpeas (Vigna unguiculata) under tropical field conditions. J. Agric. Sci. Camb. 93, 291-307.

McPherson, H.G., Warrington, I.J., Turnbull, H.L., 1985. The effects of temperature and daylength on the rate of development of pigenopea. Ann. Bot. 56, 597-611.

Narayanan, A., Saxena, N.P., Sheldrake, A.R., 1981. Varietal differences in seed size and seedling growth of pigeonpea and chickpea. Indian J. Agric. Sci. 51, 389-393.

Rawson, H.M., Constable, G.A., 1981. Gas exchange of pigeonpea: a comparison with other crops and a model of carbon production and its distribution within the plant. In: Proceedings of the International Workshop on Pigeonpeas, Vol. 1, December 15-19, 1980, ICRISAT Center, India. ICRISAT, Patancheru, AP, India, pp. 175-190.

Remanandan, P., 1990. Pigeonpea: genetic resources. In: Nene, Y.L., Hall, S.D., Sheila, V.K. (Eds.), The Pigeonpea. CAB International, Wallingford, Oxon., UK, pp. 89-117. 
Sanetra, C.M., 1996. Characterisation of leaf senescence in relation to partitioning and remobilisation of dry matter and nitrogen in pigeonpea (Cajanus cajan (L.) Millsp.) under two soil moisture regimes. M.Sc. Thesis. Institute for Agronomy and Animal Production in the Tropics, University of Goettingen, Germany, $86 \mathrm{pp}$.

Sanetra, C.M., Ito, O., Virmani, S.M., Vlek, P.L.G., 1998. Remobilization of nitrogen from senescing leaves of pigeonpea (Cajanus cajan (L.) Millsp.): genotypic differences across maturity groups. J. Exp. Bot. 49, 853-862.

Sheldrake, A.R., Narayanan, A., 1979. Growth, development and nutrient uptake in pigeonpeas (Cajanus cajan). J. Agric. Sci. Camb. 92, 513-526.

Sinclair, T.R., de Wit, C.T., 1975. Photosynthate and nitrogen requirements for seed production by various. Crop Sci. 189, $565-567$.
Singh, L., Silim, S.N., Ariyanayagam, R.P., Reddy, M.V. (Eds.), 1990. In: Proceedings of the First Eastern and Southern Africa Regional Legumes (Pigeonpea) Workshop, June 25-27, 1990, Nairobi, Kenya. Eastern Africa Regional Cereals and Legumes (EARCAL) Program, International Crops Research Institute for the Semi-Arid Tropics, PO Box 39063, Nairobi, Kenya.

Singh, L., Chauhan, Y.S., Johansen, C., Singh, S.P. (Eds.), 1996. Prospects for growing extra-short duration pigeonpea in rotation with winter crops. In: Proceedings of the IARI/ ICRISAT Workshop and Monitoring Tour, October 16-18, 1995, New Delhi, India. IARI/ICRISAT, New Delhi/Patancheru, $132 \mathrm{pp}$.

Turnbull, L.V., 1986. The role of photoperiod and temperature in early vegetative growth and floral development in selected lines of pigeonpea (Cajanus cajan (L.) Millsp.). PhD thesis, University of Queensland, Australia, 309 pp. 